\title{
Surgical Treatment of Extracranial Distal Internal Carotid Artery Dissecting Aneurysm
}

\author{
-Case Report-
}

\author{
Isao Yamamoto, Akira IKedA, Masami SHIMOdA, Shinri OdA, \\ Yoshihiro MIYAZAKI, Kaoru ITO, Shogo SHINOZUKA and Osamu SATO
}

Department of Neurosurgery, Tokai University School of Medicine, Isehara, Kanagawa

\begin{abstract}
A 53-year-old malc presented with a dissecting aneurysm of the extracranial distal internal carotid artery (ICA) treated by aneurysm removal with interposition of a saphenous vein graft. The surgical approach involved sectioning of Riolan's nosegay.
\end{abstract}

Key words: dissecting aneurysm, surgical technique, extracranial internal carotid artery, saphenous vein graft

\section{Introduction}

Extracranial carotid artery aneurysm has a varied etiology including atherosclerosis; a frequent cause, spontaneous dissection, trauma, fibromuscular dysplasia, infection, radiation, cystic medial necrosis, and Marfan's syndrome. ${ }^{19,201}$ However, aneurysms of the extracranial distal internal carotid artery (ICA) above the line between the mandibular angle and the tip of the mastoid process are uncommon, and very inaccessible to surgical approaches.

Here we report our surgical technique for exposing the extracranial distal ICA and present a case of dissecting aneurysm at this challenging location.

\section{Surgical Technique}

The patient is placed in the supine position with the head turned to the side opposite to the lesion and prepared for carotid endarterectomy. A skin incision descends from the inferior border of the zygomatic arch preauricularly, passing in front of the tragus, to the mastoid tip and extends just anterior to the sternocleidomastoid muscle down to the mid-cervical region. The subcutaneous tissue and platysma muscle are incised to expose the posteroinferior border of the parotid gland, common carotid artery and bifurcation, internal and external carotid arteries,

Received January 22, 1991; Accepted May 30, 1991 and the internal jugular vein up to the level of the hypoglossal nerve (Fig. 1). During these procedures, the facial vein and omohyoid muscle are ligated and incised if necessary. The main trunk of the facial nerve is exposed near the styloid process. The parotid gland containing the main branch of the facial nerve, the marginal mandibular branch, is then separated from the underlying masseteric fascia and retracted upward (Fig. 2). The posterior belly of the digastric muscle and the stylohyoid muscle are divided and reflected medially. The ICA is traced upward to the level of the facial nerve crossing point. Division of the occipital artery and/or ansa cervicalis of the hypoglossal nerve permits increased mobilization of the external carotid artery and hypoglossal nerve. The stylomandibular ligament is also divided to allow anterior displacement of the mandible (Fig. 3 ). Section of the styloglossus and stylopharyngeus muscles attached to the styloid process permits better exposure of the distal portion of the extracranial ICA and the lower four cranial nerves to $1 \mathrm{~cm}$ proximal to the skull base. During dissection, care should be taken not to damage the glossopharyngeal and vagus nerves, and the inferior alveolar neurovascular bundle (Fig. 4).

\section{Case Report}

A 53-year-old male with controlled hypertension was admitted with weakness in the right extremities. 


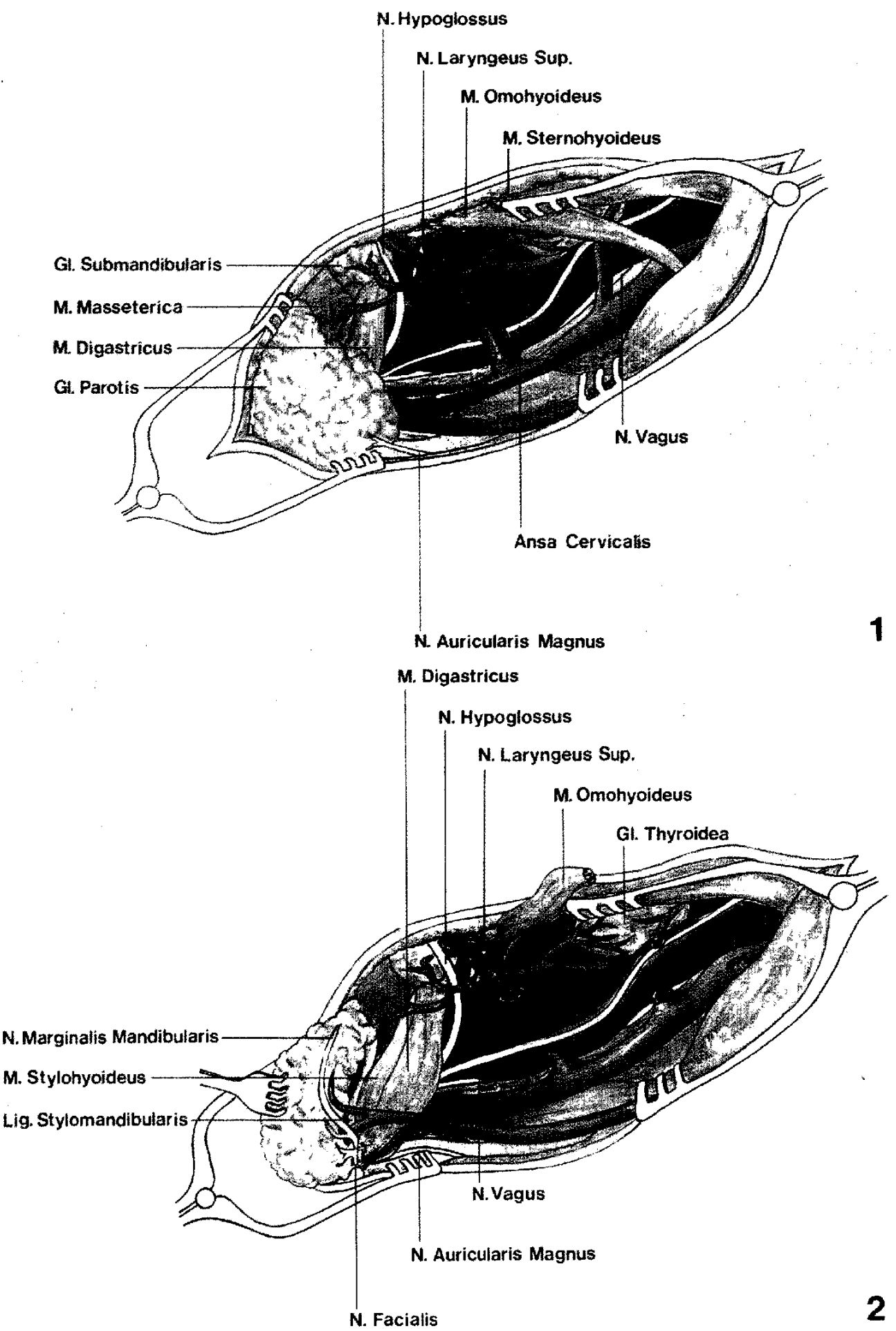

Fig. 1 The sternocleidomastoid muscle is retracted laterally to demonstrate the parotid gland, common carotid, internal and external carotid arteries, and internal jugular vein.

Fig. 2 The facial vein and the omohyoid muscle are transected, and the parotid gland is retracted upward after identification of the facial nerve, to expose the carotid artery, and the digastric and stylohyoid muscles. 

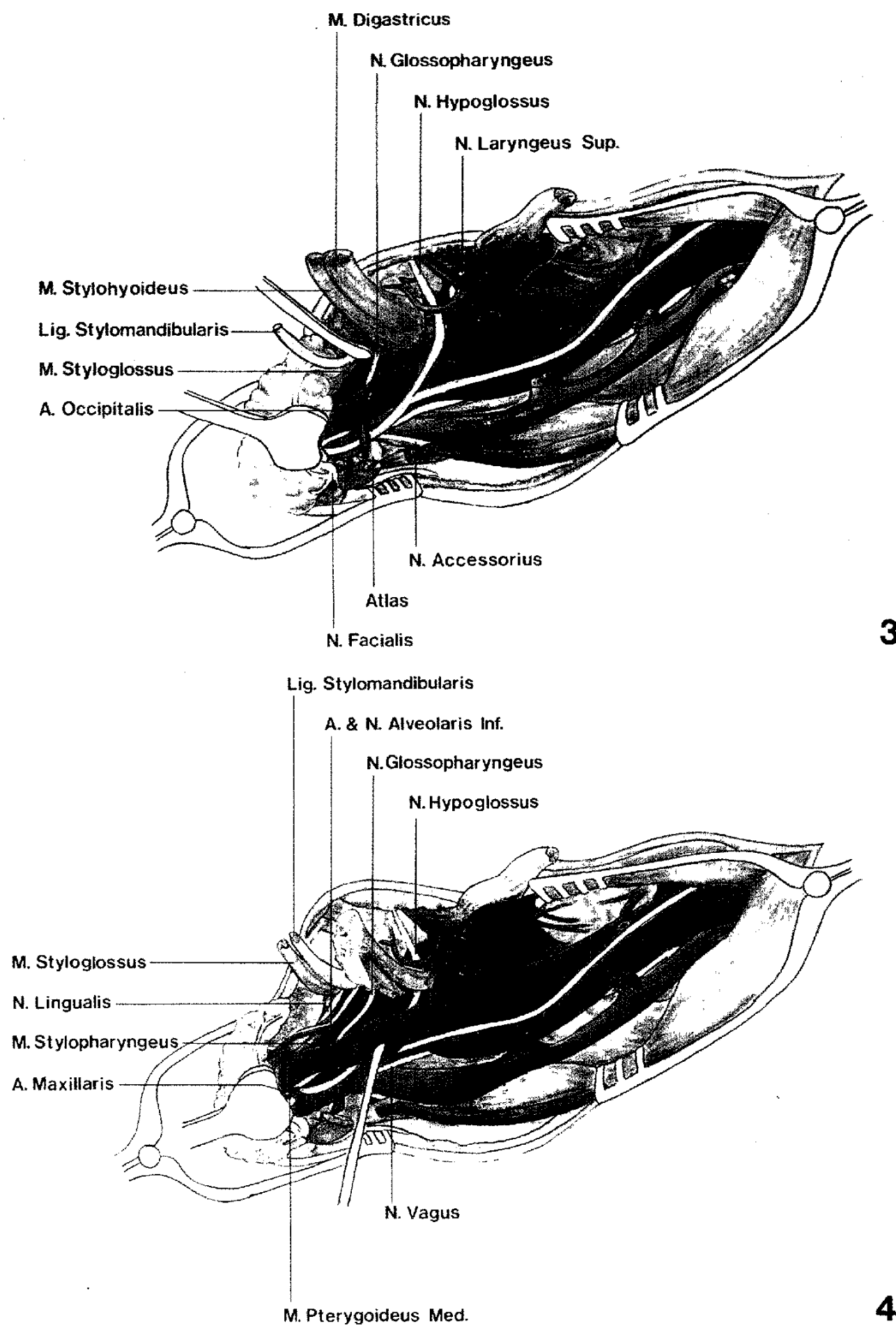

Fig. 3 The digastric and stylohyoid muscles are transected to expose the more distal carotid arteries and cranial nerves. The stylomandibular ligament is also divided and the mandible retracted anteriorly.

Fig. 4 The styloglossus and stylopharyngeus muscles, and occipital artery are transected to expose the extracranial distal internal carotid artery to $1 \mathrm{~cm}$ proximal to the skull base. 


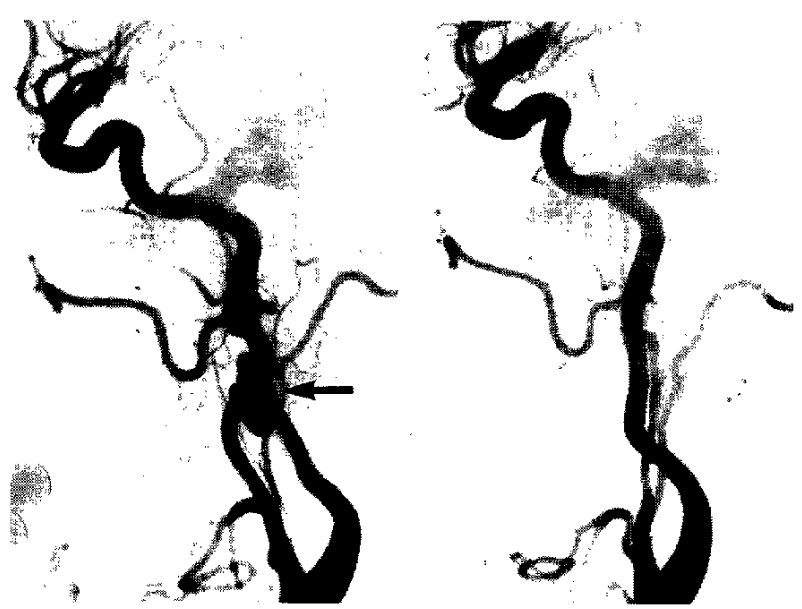

Fig. 5 left: Preoperative left carotid angiogram, lateral view, demonstrating an aneurysm of the extracranial ICA (arrow), right: Postoperative angiogram demonstrating the patency of the saphenous vein graft.

There was no contributory history of infection or trauma.

On admission, he was drowsy and disoriented. Neurological examination revealed moderate right hemiparesis with dysphasia. The drowsiness and right weakness gradually improved until he could walk unaided. A computed tomographic (CT) scan on admission revealed no abnormality, but sequential CT scans and magnetic resonance (MR) images 5 days later showed infarction in the left frontoparietal region. Left carotid angiography revealed a dissecting aneurysm of the left ICA extending from $3.5 \mathrm{~cm}$ above the bifurcation to the level of the $C 1$ vertebral arch (Fig. 5 left). A Matas test showed his neurological status and electroencephalographic (EEG) findings were unchanged after balloon occlusion of the left ICA for 20 minutes.

The technique described above exposed the fusiform shaped aneurysm extending about $1 \mathrm{~cm}$ from the skull base. The ICA was occluded proximal and distal to the aneurysm. The $2.5 \mathrm{~cm}$ long aneurysm was removed and the ends of the ICA anastomosed end-to-end with a $3 \mathrm{~cm}$ saphenous vein graft. The EEG remained normal throughout the procedure. The stump pressure was $35 \mathrm{mmHg}$ and no shunt was used. The total clamping time was 80 minutes.

Postoperatively, he developed a mild swallowing impairment and left Horner's syndrome, which gradually improved over 6 months. Follow-up angiography demonstrated complete patency of the graft (Fig. 5 right). A micrograph of the cross-sec-

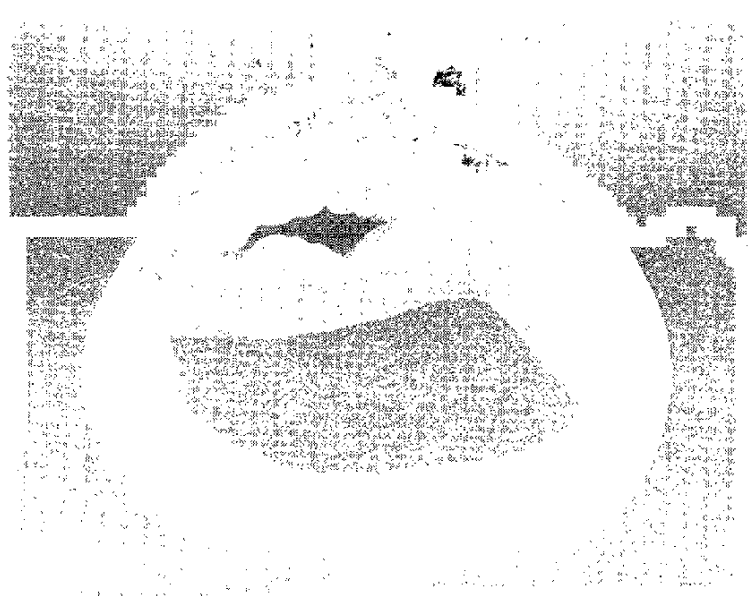

Fig. 6 Photomicrograph of the cross-section of the removed dissecting aneurysm, showing separation of the arterial media and formation of the false lumen. HE stain, $\times 40$.

tion of the removed aneurysm showed the arterial media were separated and a false lumen had formed (Fig. 6).

\section{Discussion}

Aneurysms of the distal ICA extending to near the skull base are challenging to treat surgically because direct access is difficult at this level. Anterior and lateral approaches to the extracranial segment of the carotid artery have been reported. The lateral approach allowed easy dissection of the proximal extracranial segment of the carotid artery without dividing any important neurovascular structures. ${ }^{(4)}$ However, Riolan's nosegay, ${ }^{8}$ which originates from the styloid process (stylohyoid, styloglossus, and stylopharyngeus muscles) and the muscle group attached to the mastoid process, such as the sternocleidomastoid and digastric muscles, form a rather narrow and deep field so procedures on the extracranial distal ICA are inconvenient. Various anterior approaches include removal of the mastoid process and division of the sternocleidomastoid muscle, ${ }^{1)}$ excision of the styloid process, ") and en bloc removal of the mastoid process. ${ }^{10.17)}$

However, the main obstacle to these procedures is the mandible. Several mandibular osteotomies and a mandibular subluxation have been designed ${ }^{3-9,11}$. 13,15,18,19,211 (Fig. 7). However, mandibular osteotomies almost inevitably damage the inferior alveolar nerve and the mandibular branch of the facial nerve. ${ }^{81}$ Subluxation of the mandibular condyle anteriorly to the articular eminence of the temporal bone transfers 

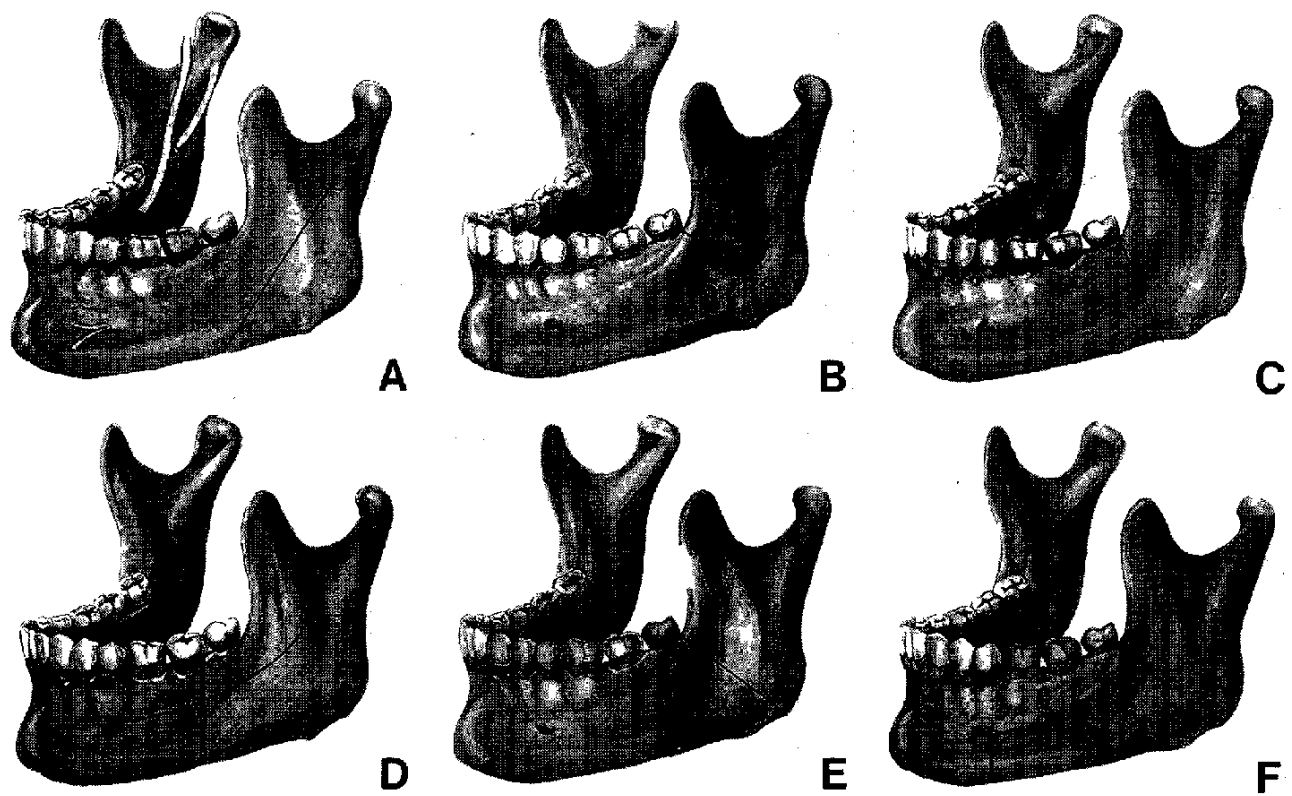

Fig. 7 Various mandibular osteotomies. A: mandibular angle resection, B,C: mandibular ramus resection, D: resection of the angle and the lateral lower half of the mandibular body, E,F: lateral mandibulotomy.

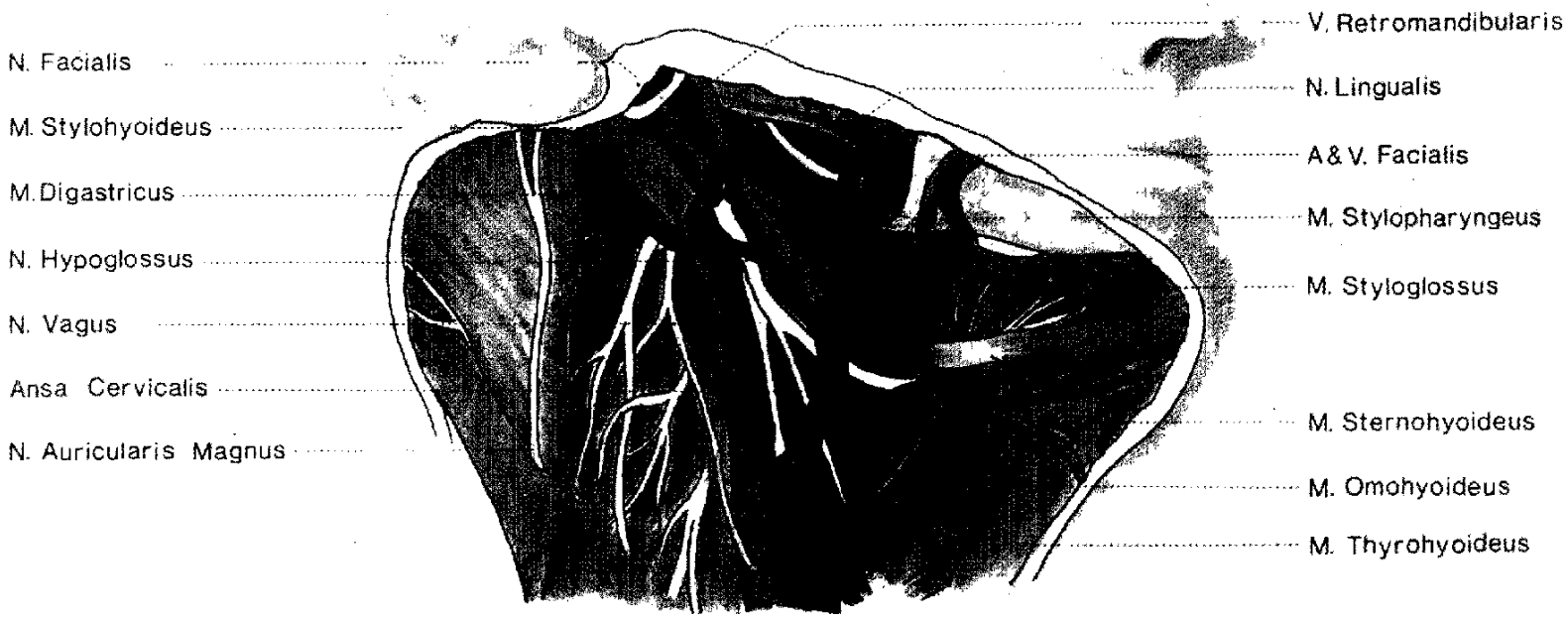

Fig. 8 Riolan's nosegay is the muscular group attached to the styloid process, including the stylohyoid, styloglossus, and stylopharyngeus muscles.

a triangular operating field into a rectangular field allowing a wide exposure. ${ }^{11)}$ However, disadvantages of mandibular subluxation include: 1) recurrent and superior laryngeal nerves and marginal mandibular nerve injury, 2) contralateral compression of the carotid sheath between the mandibular angle and the transverse vertebral process, and 3) indentation of the contralateral vagus nerve by the extreme disloca- 
tion of the ipsilateral mandible. ${ }^{11}$

Another important anatomical relationship during surgical exposure of this deep area is that of Riolan's nosegay and the neurovascular structures. ${ }^{8}$ The facial nerve runs between the digastric and stylohyoid muscles, and the external carotid artery between the stylohyoid and styloglossus muscles. The ICA, glossopharyngeal, vagus, accessory, and hypoglossal nerves and the cervical sympathetic trunk are located between the styloglossus and stylopharyngeus muscles (Fig. 8). Our study shows that sectioning of Riolan's nosegay and the posterior belly of the digastric muscle can expose the extracranial distal ICA to $1 \mathrm{~cm}$ proximal to the skull base. Division of the stylomandibular ligament, if necessary, and partial removal of the mandibular angle permits increased anterior displacement of the mandible to further improve the operative field without mandibular subluxation.

Various surgical techniques have been developed to repair extracranial ICA aneurysms..$^{2.12,13,16,17.19 .201}$ Clipping or excision with primary end-to-end anastomosis is undoubtedly the treatment of choice. However, extracranial carotid aneurysms are more often fusiform than saccular. ${ }^{19}$ Such extended dissecting aneurysms, therefore, cannot be excised with primary anastomosis. Extracranial and intracranial bypass after proximal and distal ligation of the aneurysm is not a physiologically adequate solution, which risks thrombosis and provides insufficient perfusion of the brain. The alternatives are excision of the aneurysm with interposition grafting using saphenous vein or iliac artery, and anastomosis between the external and distal ICA. Sundt et al. ${ }^{2(1)}$ reported seven cases managed by aneurysm removal with interposition saphenous vein graft as used in our case. In their series, four patients developed transient dysphagia caused by traction damage to the pharyngeal and superior laryngeal nerves, and one patient with preoperative difficulty in swallowing required gastrostomy.

The proposed surgical technique, particularly the division of the stylomandibular ligament, as recommended by Sundt et al. ${ }^{201}$ and Cantore et al.,${ }^{8)}$ should be considered as a possible approach to extracranial distal ICA lesions.

\section{References}

1) Arnulf G: Pathologie et Chirurgie des Carotides. Paris, Masson et Cie, 1957, p 144

2) Ausman JI, Pearce JE, Reyes RA, Schanz G: Treatment of a high extracranial carotid artery aneurysm with CCA-MCA bypass and carotid ligation. $J$
Neurosurg 58: 421-424, 1983

3) Baker DC, Conley J: Treatment of massive deep lobe parotid tumors. Am J Surg 138: 572-575, 1979

4) Balaqura S, Carter JB, Gassetta DL: Surgical approach to the high subcranial internal carotid artery. Neurosurgery 16: 402-405, 1985

5) Batzdorf U, Gregorius FK: Surgical exposure of the high cervical carotid artery: Experimental study and review. Neurosurgery 13: 657-661, 1983

6) Beall AC, Crawford ES, Cooley DA, DeBakey ME: Extracranial aneurysms of the carotid artery: Report of seven cases. Postgrad Med 32: 93-100, 1962

7) Biller HF, Shugar JMA, Krespi YP: A new technique for wide-field exposure of the base of the skull. Arch Ololaryngol 107: 698-702, 1981

8) Cantore GP, Delfini R, Mariottini A, Santoro A, Cascone P: Anterior displacement of the mandible for better exposure of the distal segment of the extracranial carotid artery. Acta Neurochir (Wien) 86: $56-60,1987$

9) Dichtel WJ, Miller HR, Woodson GE, Feliciano DV, Hurt J: Lateral mandibulotomy: A technique of exposure for penetrating injurics of the internal carotid artery of the base of the skull. Laryngoscope 94: 1140-1144, 1984

10) Fisch UP, Oldring DJ, Senning A: Surgical therapy of internal carotid artery lesions of the skull base and temporal bone. Otolaryngol Head Neck Surg 88: $548-554,1980$

11) Fisher DF, Clagett GP, Parker JI, Fry RE, Poor MR, Finn RA, Brink BE, Fry WJ: Mandibular subluxation for high carotid exposure. J Vasc Surg 1: 727733,1984

12) Hardin CA, Snodgrass RG: Dissecting aneurysm of internal carotid artery treated by fenestration and graft. Surgery 55: 207-209, 1964

13) Hershey FB: Operation for aneurysm of the internal carotid artery high in the neck: $A$ new and an old technique. Angiology 25: 24-30, 1974

14) Krajicek M, Kramar R: The lateral approach to the extracranial segment of the carotid artery. $J$ Cardiovasc Surg (Torino) 9: 302-304, 1968

15) McGregor IA, MacDonald DG: Mandibular osteotomy in surgical approach to the oral cavity. Head Neck Surg 5: 457-467, 1983

16) Pellegrini RV, Manzetti GW, DiMarco RF, Bekoe S, Arena SA, Marrangoni AG: The direct surgical management of lesions of the high internal carotid artery. J Cardiovasc Surg (Torino) 25: 29-35, 1984

17) Purdue GF, Pellegrini RV, Arena S: Aneurysms of the high internal carotid artery: A new approach. Surgery 89: 268-270, 1981

18) Spiro RH, Gerald FP, Strong EW: Mandibular "swing" approach for oral and otolaryngeal tumors. Head Neck Surg 3: 371-378, 1981

19) Stoney RJ, Qvarfordt PG: Accessible and inaccessible aneurysms of the extracranial carotid artery, in Moore WS (ed): Surgery for Cerebrovascular Disease. Edinburgh, Churchill Livingstone, 1987, pp 
$567-577$

20) Sundt TM Jr, Pearson BW, Piepgras DG, Houser OW, Mokri B: Surgical management of aneurysms of the distal extracranial internal carotid artery. $J$ Neurosurg 64: 169-182, 1986

21) Welsch P, Pradier R, Repetto R: Fibromuscular dysplasia of the distal cervical internal carotid artery. $J$ Cardiovasc Surg (Torino) 22: 321-326, 1981
Address reprint requests to: I. Yamamoto, M.D., Department of Neurosurgery, Tokai University School of Medicine, Bohseidai, Isehara, Kanagawa 259-11, Japan. 